\title{
Characteristics of Diabetics with Poor Glycemic Control Who Achieve Good Control
}

\author{
Michal Shani, MD, MPH, Tomas R. Taylor, MD, PhD, Shlomo Vinker, MD, \\ Alexander Lustman, MD, Rina Erez, MD, Asher Elhayany, MD, MPA, and \\ Amnon Lahad, MD, MPH
}

Objective: To find the characteristics of diabetics with poorly controlled diabetes that became well controlled compared with the patients with poorly controlled diabetes that remained poorly controlled.

Methods: The sample included diabetic patients, aged 40 years and older, from the Central district of Clalit Health Service in Israel, with at least one HbA1c measure greater than $9.5 \mathrm{mg} \%$ during 2001 . They were divided into 2 categories according to their HbA1c levels in 2003, well controlled (HbA1c $<7.5$ $\mathrm{mg} \%$ ) and poorly controlled (HbA1c $>9.5 \mathrm{mg} \%$ ). Patients with $7.5<\mathrm{HbA1c}<9.5$ in 2003 were excluded from analysis.

Results: Two thousand sixty-two diabetic patients met the inclusion criteria and care was provided by one of 249 primary care physicians. Of these patients, 1232 (41.6\%) had well-controlled diabetes and 1760 (58.4\%) had poorly controlled diabetes in 2003 . The well-controlled group had fewer patients with low socioeconomic status $(30.3 \%$ vs $41.9 \% ; P<.001)$ and more men $(52 \%$ vs $43.8 \% ; P<.001)$. The individual primary care physician was the most significant predictor of good glycemic control. Total patient costs in 2004 were $8 \%$ lower among the group with well-controlled diabetes.

Conclusion: The primary care physician has an important role in the patient's chances of achieving glycemic control. Further investigation of how and why some primary care physicians achieve better diabetes control in their patients would be worthwhile. (J Am Board Fam Med 2008;21:490-6.)

Care of diabetic patients requires many resources and places a great economic burden on society. The prevalence of diabetes among Israeli adults in1998 was 6.1 of $100^{1}$ and the prevalence of diabetes among the Israeli general population in 2000 was 3.4 of $100 .^{2}$ According to the Israeli Diabetes Association, this accounts for approximately 250,000

This article was externally peer reviewed.

Submitted 2 December 2007; revised 10 March 2008; accepted 17 March 2008.

From the Department of Family Medicine, Central District, Clalit Health Service (MS, AL, RE, AE), Rehovot; the Department of Family Medicine, Sackler Faculty of Medicine, Tel Aviv University (MS, SV), Israel; the Department of Family Medicine, University of Washington, Seattle (TRT); and the Department of Family Medicine, Hadassah Medical School, Hebrew University, Jerusalem, Israel.

Funding: none.

Conflict of interest: none declared.

Corresponding author: Dr. Michal Shani, 7 Rodavsky St., 76804 Mazkeret Batya, Israel (E-mail: michal.shani@gmail.com).

\footnotetext{
See Related Commentary on Page 487.
}

patients nationwide. ${ }^{3}$ It has been estimated that $10 \%$ of diabetic patients in Israel are undiagnosed, ${ }^{4}$ so the actual number of diabetic patients is most likely higher.

Good glycemic control reduces mortality and long-term complications of diabetes. ${ }^{5-9}$ Predictors such as medication adherence, ${ }^{10,11}$ physical activity, ${ }^{12,13}$ family support, ${ }^{14,15}$ and coping mechanisms ${ }^{16}$ have been correlated with diabetic control.

Little is known about the predictors that influence changes in glycemic control among patients with poorly controlled diabetes. We used the computerized database of Clalit Health Service (CHS) to identify characteristics that were associated with improvements in diabetic control.

Defining the characteristics of patients with poorly controlled diabetes that became well controlled may reveal new predictors related to achieving good glycemic control. This information will help with planning better intervention programs for diabetic patients in the future.

CHS is the largest health maintenance organization (HMO) in Israel, serving over $50 \%$ of the Israeli 
population. Patient records have been completely computerized for over 8 years. The CHS central database includes demographic data, working diagnoses, laboratory results, and administrative data relating to the primary care physician, primary care clinic, and costs. CHS Central district serves approximately 500,000 patients from all socioeconomic levels. Over 24,000 diabetic patients are registered in the district database. The working diagnosis of "diabetes mellitus" detects over $90 \%$ of the known diabetics ${ }^{2}$

Access to a primary care physician is universal in Israel. Every person insured by CHS is assigned to a primary care physician. The primary care physician is responsible for all routine follow-ups, including diabetic care. There are no copayments for any procedure within the primary care clinic, including primary care physician visits. There is a very small copayment (approximately US\$3) for an ophthalmologic check up. Each primary care clinic is managed by a primary care physician who is one of the clinic staff.

This descriptive study follows the care of diabetic patients within their primary care setting while receiving their usual care. The objective was to define the characteristics of diabetics who had poor glycemic control in 2001 and achieved good control by 2003 compared with the patients with poor glycemic control in 2001 who still had poor glycemic control in 2003 .

\section{Methods}

The study was conducted in the Central district of CHS in Israel, and received local ethics committee approval.

\section{Population}

The study population included all diabetic patients, older than 40 years of age with at least one HbA1c measure $>9.5 \mathrm{mg} \%$ during 2001, who were still alive and insured by CHS in 2003 .

This group was divided into 3 categories according to their last $\mathrm{HbA1c}$ measure in 2003. Patients with $\mathrm{HbA1c}<7.5 \mathrm{mg} \%$ were considered to be well controlled. Patients with HbA1c $>9.5 \mathrm{mg} \%$ were considered to be poorly controlled. Patients with HbA1c between 7.5 and $9.5 \mathrm{mg} \%$ were excluded from further analysis.

The value of $\mathrm{HbAlc}>9.5 \mathrm{mg} \%$ was chosen to make sure that only diabetic patients with very poorly controlled diabetes would be included in this study. HbA1c of $<7.5 \mathrm{mg} \%$ was chosen to enlarge the well-controlled group. The intermediate group was excluded from the study in advance to sharpen the differences.

\section{Patient Demographics}

The following data were collected for each patient: age (in 2001), gender, place of birth, and socioeconomic status. Patients exempt from paying the monthly National Insurance contribution were defined as being of low socioeconomic status. This exemption from payments is given by the National Insurance according to income. The information about the exemption is retrieved directly from the National Insurance database. This marker of low socioeconomic status was used by the quality indicators national program. ${ }^{17}$

\section{Administrative Data}

Data about the primary care physicians was collected, including demographics (including age, gender, place of birth, medical school, years since graduation from medical school, years of working at the HMO, and the physicians' managerial responsibilities); changing the primary care physician during the study period; and primary care clinic size (small, $<5,000$ patients; intermediate, 5,000 to 10,000 patients; large, $>10,000$ patients).

Medication costs and total patient costs in 2001 and in 2004 (1 year after diabetes control had been achieved/not achieved) were calculated as US\$ (fixed prices). Costs were measured as the costs to the HMO. A log of the costs was used in an attempt to normalize the distribution of the costs.

\section{Health Determinants}

Health determinants include the number of chronic disease diagnoses other than diabetes, according to the chronic diseases register, the number and duration of hospitalizations from any cause in 2001 and in 2004, and mortality after 2003.

\section{Diabetes Follow-up}

Follow-up included low-density lipoprotein (LDL) cholesterol examination and calculated LDL cholesterol values for 2001 and 2004; ophthalmologist visits in 2001 and 2004 (fundus examination as part of diabetes follow-up is done in Israel routinely by ophthalmologists); and microalbumin examination in 2004 (because microalbumin examinations were evaluated using more than one method in 2001 the information was not included). All laboratory tests 


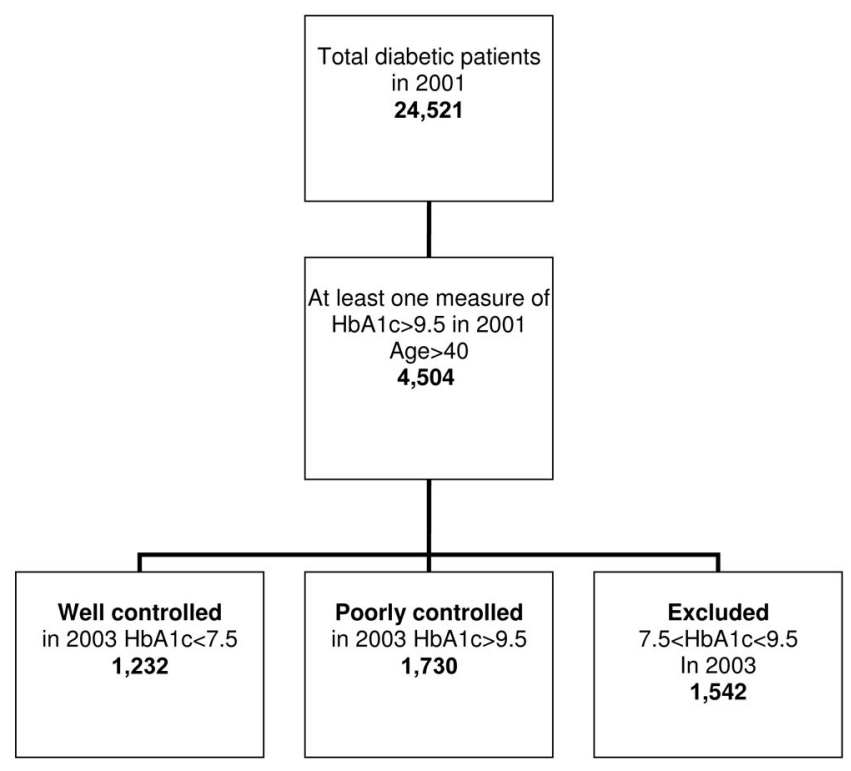

Figure 1. Study design.

were performed in the districts' central laboratory and results were sent directly to the patient's electronic medical files.

\section{Statistics}

$\chi^{2}$ and $t$ tests were used for the comparisons of each variant. Logistic regression was used to evaluate the relationship between predictors. The dependent variable was the glycemic control in 2003. STATA software, version 8.0 (Stata Corporation, College Station, TX) was used for all statistical analysis.

\section{Results}

Four thousand five hundred four diabetic patients older than 40 years of age had at least one measure of
HbA1c $>9.5 \mathrm{mg} \%$ in 2001. Of these, 1542 patients were excluded from further analysis because their HbA1c measure in 2003 was between 7.5 and 9.5 $\mathrm{mg} \%$. A total of 2962 patients were included in the study. Of these, 1232 patients were considered to have well-controlled diabetes and 1730 were considered to have poorly controlled diabetes (see Figure 1).

\section{Patient Characteristics and Good Glycemic Control (Table 1)}

Men were more likely than women to achieve wellcontrolled diabetes $(52 \%$ vs $43.6 \% ; P<.001)$. The average age of those who achieved well-controlled diabetes was slightly younger than that of those

Table 1. Patient Characteristics by Glycemic Control

\begin{tabular}{|c|c|c|c|c|}
\hline & $\begin{array}{l}\text { Entire Cohort } \\
(\mathrm{n}=2,962)\end{array}$ & $\begin{array}{l}\text { Well-controlled Diabetes } \\
\qquad(\mathrm{n}=1,232)\end{array}$ & $\begin{array}{l}\text { Poorly Controlled Diabetes } \\
\qquad(\mathrm{n}=1,730)\end{array}$ & $P$ \\
\hline Age (mean years \pm SD) & $63.9 \pm 10.3$ & $63.2 \pm 10.2$ & $64.5 \pm 10.4$ & $<.001$ \\
\hline Gender (\% men) & 47.1 & 52 & 43.8 & $<.001$ \\
\hline Place of birth (\%) & & & & NS \\
\hline Israel & 19 & 18.1 & 19.7 & \\
\hline Europe & 32.3 & 32.8 & 32 & \\
\hline Africa & 25.6 & 25.1 & 26 & \\
\hline Asia & 22.1 & 22.7 & 21.6 & \\
\hline America & 0.9 & 1.3 & 0.7 & \\
\hline Low socioeconomic status (\%) & 37 & 30.3 & 41.9 & $<.001$ \\
\hline $\begin{array}{l}\text { Other chronic diagnosis (average) } \\
(\mathrm{n} \text { [median]) }\end{array}$ & $3.8(3)$ & $3.7(3)$ & $3.9(3)$ & NS \\
\hline $\begin{array}{l}\text { Death during last year of follow- } \\
\text { up (\%) }\end{array}$ & 6.9 & 6.8 & 6.9 & NS \\
\hline
\end{tabular}




\begin{tabular}{|c|c|c|c|c|}
\hline & $\begin{array}{l}\text { Entire Cohort } \\
(\mathrm{n}=2,962)\end{array}$ & $\begin{array}{l}\text { Well-controlled Diabetes } \\
\qquad(\mathrm{n}=1,232)\end{array}$ & $\begin{array}{l}\text { Poorly Controlled Diabetes } \\
\qquad(\mathrm{n}=1,730)\end{array}$ & $P$ \\
\hline \multicolumn{5}{|l|}{ Primary care clinics $(\mathrm{n}=132)$} \\
\hline \multicolumn{5}{|l|}{ Clinic size (\%) } \\
\hline Small & 15.1 & 16 & 14.5 & $<.001$ \\
\hline Intermediate & 49.7 & 59.2 & 42.8 & \\
\hline Large & 35.2 & 24.8 & 42.7 & \\
\hline \multicolumn{5}{|l|}{ Primary care physician $(\mathrm{n}=249)$} \\
\hline Board-certified physician & $43.4 \%$ & $44 \%$ & $43 \%$ & NS \\
\hline Female & $55.7 \%$ & $56 \%$ & $55.4 \%$ & NS \\
\hline Age (years) (mean) & 47.6 & 47.3 & 47.7 & NS \\
\hline Years since graduation (mean) & 23.2 & 22.6 & 23.5 & NS \\
\hline Years in Clalit Health Service (mean) & 15.1 & 14.9 & 15.3 & NS \\
\hline Birthplace (\%) & & & & NS \\
\hline Former USSR & 61.1 & 58.1 & 63 & \\
\hline Israel & 18.9 & 21.3 & 17.4 & \\
\hline Rumania & 10.5 & 10.9 & 10.3 & \\
\hline Argentina & 3.5 & 3.2 & 3.7 & \\
\hline USA & 3.4 & 3.4 & 3.4 & \\
\hline Other & 2.5 & 3.1 & 2.1 & \\
\hline Location of medical school (\%) & & & & NS \\
\hline Former USSR & 59.2 & 56.5 & 60.8 & \\
\hline Israel & 17.9 & 19.9 & 16.8 & \\
\hline Rumania & 9.5 & 9.6 & 9.5 & \\
\hline Italy & 4.9 & 4.9 & 4.9 & \\
\hline Other & 8.4 & 9 & 7.9 & \\
\hline Clinic manager (\%) & 19.3 & 22 & 17.2 & .001 \\
\hline Changed primary care physician (\%) & 29.7 & 27.7 & 31.1 & .044 \\
\hline
\end{tabular}

*Univariate analysis. All data provided as percent.

who maintained poorly controlled diabetes $(63.2 \%$ vs $64.5 \% ; P<.001)$. There were fewer patients from a low socioeconomic status in the well-controlled group compared with those patients in the poorly controlled group. There was no difference between the groups relating to origin, the number of other chronic diseases (besides diabetes), or mortality rate.

\section{Physician and Clinic Characteristics and Good Glycemic Control (Table 2)}

The patients' primary care physician was highly correlated with good glycemic control in any combination of predictors in the logistic regression (physicians were entered as a catregorical variable in the analysis). There was a full spectrum of results related to physicians' outcomes. Although some physicians had all of their patients with poorly controlled diabetes in 2001 become well controlled in 2003, others had none. None of the primary care physician characteristics were related to glycemic control except being a clinic manager.

The primary care clinic to which the patient belonged was highly correlated with good glycemic control $(P<.001)$. Smaller (small and intermediate size) clinics had a slightly higher percentage of patients who achieved well-controlled diabetes compared with large clinics.

Patients from the group with poorly controlled diabetes were more likely to change their primary care physician (because of patients' choice or physician replacement) than patients from the group with well-controlled diabetes $(31.1 \%$ vs $27.7 \%$; $P=.044)$.

\section{Diabetes Follow-up (Table 3)}

Patients who had poorly controlled diabetes in 2003 were more likely to have a better diabetes follow-up in 2004 compared with those who were well controlled in 2003. Among the patients with 


\begin{tabular}{|c|c|c|c|c|}
\hline & $\begin{array}{c}\text { Entire Cohort } \\
(\mathrm{n}=2,962)\end{array}$ & $\begin{array}{c}\text { Well-controlled } \\
\text { Diabetes } \\
(\mathrm{n}=1,232)\end{array}$ & $\begin{array}{c}\text { Poorly Controlled } \\
\text { Diabetes } \\
(\mathrm{n}=1,730)\end{array}$ & $P$ \\
\hline Ophthalmologist visit 2001 (\%) & 54.1 & 54.5 & 53.8 & NS \\
\hline Ophthalmologist visit 2004 (\%) & 57.9 & 55.5 & 59.6 & .025 \\
\hline LDL cholesterol examination 2001 (\%) & 81.5 & 82.7 & 80.6 & NS \\
\hline LDL cholesterol examination 2004 (\%) & 85.5 & 82.8 & 87.3 & $<.001$ \\
\hline Average LDL cholesterol 2001 (mg\%) & $118.6 \pm 35.2$ & $116.6 \pm 35.1$ & $120.1 \pm 36.7$ & .01 \\
\hline Average LDL cholesterol 2004 (mg\%) & $107.1 \pm 34.4$ & $103.1 \pm 31.2$ & $109.8 \pm 36.1$ & $<.001$ \\
\hline Urine microalbumine examination in 2004 (\%) & 70.8 & 68.2 & 72.6 & .009 \\
\hline
\end{tabular}

LDL, low-denisty lipoprotein.

poorly controlled diabetes in 2003, 59.6\% visited the ophthalmologist vs $55.5 \%$ of patients in the group with well-controlled diabetes $(P=.025)$; microalbumin was checked in $72.6 \%$ vs $68.2 \%(P=$ .009). LDL cholesterol was checked in $87.3 \%$ vs 82.8\% $(P<.001)$, but average LDL cholesterol was significantly lower in the well-controlled group $(103.1$ vs $109.8 ; P<.001)$ using both $t$ test and a pair-wise comparison.

\section{Patient Costs (Table 4)}

There were no differences in patient hospitalizations, average drug costs, or average total cost between the 2 groups in 2001. A higher percentage of patients in the group with poorly controlled diabetes were hospitalized during 2004 (34.9\% vs $31.1 \%$; $P=.033)$. The average patient cost was $8 \%$ lower in 2004 among patients in the well-controlled group compared with the poorly controlled group, although the average drug costs were higher for those in the well-controlled group compared with those in the poorly controlled group in the basis year 2001. Using a $\log$ of costs, only the total patient cost in 2004 had a borderline significance.

\section{Discussion}

A good primary care physician is valuable not just to their patients but also to the health system. We found that a patient's primary care physician was the strongest predictor of the patient's likelihood to achieve well-controlled diabetes. Apart from the benefit to the patient of improved glycemic control, the importance of glycemic control to the health system is clear, with observed cost reductions in the group with good glycemic control after up to 2 years. There was a clear trend of reduction in total patient costs in 2004 among those in the group with well-controlled diabetes compared with those patients in the poorly controlled group, although

Table 4. Patient Costs by Glycemic Control

\begin{tabular}{|c|c|c|c|c|}
\hline & $\begin{array}{l}\text { Entire Cohort } \\
(\mathrm{n}=2,962)\end{array}$ & $\begin{array}{c}\text { Well-controlled } \\
\text { Diabetes } \\
(\mathrm{n}=1,232)\end{array}$ & $\begin{array}{c}\text { Poorly Controlled } \\
\text { Diabetes } \\
(\mathrm{n}=1,730)\end{array}$ & $P$ \\
\hline $\begin{array}{l}\text { Patients hospitalized in } 2001 \\
\quad(\%)\end{array}$ & 25.7 & 26.4 & 25.1 & NS \\
\hline Average drug cost 2001* (US\$) & $408 \pm 766(225)$ & $440 \pm 957(225)$ & $388 \pm 599(225)$ & NS \\
\hline $\begin{array}{l}\text { Average total patient cost } 2001^{*} \\
\text { (median) }\end{array}$ & $1793 \pm 3646(429)$ & $1885 \pm 3875(422)$ & $1738 \pm 3496(438)$ & NS \\
\hline Patients hospitalized 2004 (\%) & 33.3 & 31.1 & 34.9 & .033 \\
\hline $\begin{array}{l}\text { Average drug cost } 2004 \\
\text { (median) }\end{array}$ & $634 \pm 1338(374)$ & $647 \pm 1209(323)$ & $625 \pm 1423(376)$ & NS \\
\hline $\begin{array}{l}\text { Average total patient cost } 2004 \\
\text { (median) }\end{array}$ & $2265 \pm 4014(622)$ & $2157 \pm 4008(534)$ & $2342 \pm 4018(687)$ & NS \\
\hline Log total patient cost 2004 & & & & .075 \\
\hline
\end{tabular}

\$US $=4.4$ NIS.

*Fixed 2004 prices, in US\$. 
the costs of medications were similar in both groups. This is probably attributed to the hospitalization rate reduction noted in 2004. These findings are compatible with other findings about health care costs and improved glycemic control. ${ }^{18}$

None of the physicians' individual characteristics (such as age, gender, years in medicine, etc) were related to the achievement of good glycemic control. It seems reasonable to assume that characteristics such as good communication skills, enthusiasm, and care-which cannot be measured by the official "hard" database—may be behind the differences between individual primary care physicians and improving diabetic control. A hint to the importance of the interpersonal relationship is shown by the fact that clinic managers reached better glycemic control among their patients compared with physicians who did not have managerial responsibilities. The clinic manager is an example of a local authority within the clinic and as such has a greater influence over his/her patients. However, it might be that dealing with quality assessment on a routine basis increases their awareness and drive to improve glycemic control. Another indication of the importance of interpersonal relationships between the clinic team and the patient is that patients in large clinics have a lower probability of achieving well-controlled diabetes compared with patients in smaller and more intimate clinics.

Diabetes follow-up in 2004 improved compared with the follow-up in 2001 among both groups. Similar results were noted after intense team education for diabetes in another district in our HMO in 2002. ${ }^{19}$ It was noted that diabetes follow-up measures among patients with poorly controlled diabetes were better then those for well-controlled patients. This reflects the endless efforts invested in these patients by the primary care physicians.

We found that several patient characteristics are associated with an improvement in glycemic control. Patients from higher socioeconomic levels and men more often achieved well-controlled diabetes. This fits with other published findings that diabetic women received less aspirin and their blood pressure and LDL cholesterol levels were less likely to be controlled compared with men. ${ }^{20}$ Lower socioeconomic status was also found to be related to higher rates of obesity, hyperlipidemia, and poorly controlled diabetes. ${ }^{21}$ It is important to note that the primary care physician remained an important independent association even when these factors were included in the regression model.

There are a number of limitations to this kind of study. First, this study relies on working database information. Although the accuracy of the specific variables chosen is high, there is no information about interpersonal relationships, patient compliance to lifestyle modifications, and physician efforts as related to diabetes follow-up and control. Some important information might have been lost because of the excluded intermediate group. Moreover, because this is a retrospective cohort the results cannot be seen as causative but as related.

We did not include in our model the information about the total number of diabetic patients physicians have. A physician might have a large number of patients with well-controlled diabetes at the first sampling point (who were not included in this study from the beginning) and the group of the patients with poorly controlled diabetes does not represent well the physician's actual work. It might be that, for some physicians, only the most noncompliant patients were included in this study and this does not reflect their daily work. Patients who died during the follow-up period or who changed their HMO were excluded from the study. They might also represent a different group of patients. Diabetes follow-up requires teamwork among nurses, dieticians, endocrinologists, and pharmacists. There is no direct information about the teamwork in this study, although that the clinic is a significant predictor of glycemic control might give a hint to the importance of teamwork. In addition, we did not analyze the exact magnitude of the improvement of HbA1c or its relation to the primary care physician.

\section{Conclusion}

The primary care physician who takes care of the diabetic patient has an important role in the patient's chances of achieving glycemic control. Improving glycemic control not only improves morbidity and mortality but also reduces patient costs. Further investigation of how and why some primary care physicians achieve better diabetic control among their patients would be worthwhile. Is it because of their teamwork with other health care professionals or their own knowledge, skills, and motivation? It seems both medically and economically prudent for the health system to invest in 
primary care physician education and training to enable all primary care physicians to maximize the glycemic control of their diabetic patients.

\section{References}

1. Rennert G, Peterburg Y. Prevalence of selected chronic diseases in Israel. Isr Med Assoc J 2001;3: 404-8.

2. Israeli Ministry of Health Statistics. Morbidity. Available at http://www.health.gov.il/Download/ pages/Morbidity.pdf. Accessed 23 September 2008.

3. Israeli Diabetes Association [Homepage]. Available at http://www.sukeret.co.il/. Accessed 23 September 2008.

4. Stern E, Raz I, Weitzman S. Prevalence of diabetes mellitus among workers in Israel: a nation-wide study. Acta Diabetol 1999;36:169-72.

5. The effect of intensive treatment of diabetes on the development and progression of long-term complications in insulin-dependent diabetes mellitus. The Diabetes Control and Complications Trial Research Group. N Engl J Med 1993;329:977-86.

6. Nathan DM, Cleary PA, Backlund JY, et al. Intensive diabetes treatment and cardiovascular disease in patients with type 1 diabetes. N Engl J Med 2005; 353:2643-53.

7. Intensive blood-glucose control with sulphonylureas or insulin compared with conventional treatment and risk of complications in patients with type 2 diabetes (UKPDS 33). UK Prospective Diabetes Study (UKPDS) Group. Lancet 1998;352:837-53.

8. Effect of intensive blood-glucose control with metformin on complications in overweight patients with type 2 diabetes (UKPDS 34). UK Prospective Diabetes Study (UKPDS) Group. Lancet 1998;352:854-65.

9. Andersson DK, Svardsudd K. Long-term glycemic control relates to mortality in type II diabetes. Diabetes Care 1995;18:1534-43.

10. Schectman JM, Nadkarni MM, Voss JD. The association between diabetes metabolic control and drug adherence in an indigent population. Diabetes Care 2002;25:1015-21.

11. Winkler A, Teuscher AU, Mueller B, Diem P. Mon- itoring adherence to prescribed medication in type 2 diabetic patients treated with sulfonylureas. Swiss Med Wkly 2002;132:379-85.

12. Yamanouchi K, Shinozaki T, Chikada K, et al. Daily walking combined with diet therapy is a useful means for obese NIDDM patients not only to reduce body weight but also to improve insulin sensitivity. Diabetes Care 1995;18:775-8.

13. Kirk A, Mutrie N, MacIntyre P, Fisher M. Increasing physical activity in people with type 2 diabetes. Diabetes Care 2003;26:1186-92.

14. Cardenas L, Vallbona C, Baker S, Yusim S. Adult onset diabetes mellitus: glycemic control and family function. Am J Med Sci 1987;293:28-33.

15. Konen JC, Summerson JH, Dignan MB. Family function, stress, and locus of control. Relationships to glycemia in adults with diabetes mellitus. Arch Fam Med 1993;2:393-402.

16. Turan B, Osar Z, Molzan Turan J, Damci T, Ilkova $H$. The role of coping with disease in adherence to treatment regimen and disease control in type 1 and insulin treated type 2 diabetes mellitus. Diabetes Metab 2002;28:186-93.

17. State of Israel Ministry of Health. Quality indicators for community health care in Israel. Public report 20052007. Available at http://www.health.gov.il/pages/ default.asp? maincat $=1 \&$ catId $=98 \&$ PageId $=4215$. Accessed 3 October 2008.

18. Wagner EH, Sandhu N, Newton KM, McCulloch DK, Ramsey SD, Grothaus LC. Effect of improved glycemic control on health care costs and utilization. JAMA 2001;285:182-9.

19. Stern E, Benbassat CA, Goldfracht M. Impact of a two-arm educational program for improving diabetes care in primary care centres. Int J Clin Pract 2005;59:1126-30.

20. Wexler DJ, Grant RW, Meigs JB, Nathan DM, Cagliero E. Sex disparities in treatment of cardiac risk factors in patients with type 2 diabetes. Diabetes Care 2005;28:514-20.

21. Larranaga I, Arteagoitia JM, Rodriguez JL, et al. Socio-economic inequalities in the prevalence of Type 2 diabetes, cardiovascular risk factors and chronic diabetic complications in the Basque Country, Spain. Diabet Med 2005;22:1047-53. 